\title{
Using a vector pool containing variable-strength promoters to optimize protein production in Yarrowia lipolytica
}

\author{
Rémi Dulermo *, François Brunel, Thierry Dulermo, Rodrigo Ledesma-Amaro, Jérémy Vion, Marion Trassaert, \\ Stéphane Thomas, Jean-Marc Nicaud ${ }^{*}$ and Christophe Leplat ${ }^{*}$
}

\begin{abstract}
Background: The yeast Yarrowia lipolytica is an increasingly common biofactory. To enhance protein expression, several promoters have been developed, including the constitutive TEF promoter, the inducible POX2 promotor, and the hybrid hp4d promoter. Recently, new hp4d-inspired promoters have been created that couple various numbers of UAS1 tandem elements with the minimal LEU2 promoter or the TEF promoter. Three different protein-secretion signaling sequences can be used: preLip2, preXpr2, and preSuc2.

Results: To our knowledge, our study is the first to use a set of vectors with promoters of variable strength to produce proteins of industrial interest. We used the more conventional TEF and hp4d promoters along with five new hybrid promoters: 2UAS1-pTEF, 3UAS1-pTEF, 4UAS1-pTEF, 8UAS1-pTEF, and hp8d. We compared the production of RedStar2, glucoamylase, and xylanase $C$ when strains were grown on three media. As expected, levels of RedStar2 and glucoamylase were greatest in the strain with the 8UAS1-pTEF promoter, which was stronger. However, surprisingly, the 2UAS1-pTEF promoter was associated with the greatest xylanase $\mathrm{C}$ production and activity. This finding underscored that stronger promoters are not always better when it comes to protein production. We therefore developed a method for easily identifying the best promoter for a given protein of interest. In this gateway method, genes for YFP and a-amylase were transferred into a pool of vectors containing different promoters and gene expression was then analyzed. We observed that, in most cases, protein production and activity were correlated with promoter strength, although this pattern was protein dependent.
\end{abstract}

Conclusions: Protein expression depends on more than just promoter strength. Indeed, promoter suitability appears to be protein dependent; in some cases, optimal expression and activity was obtained using a weaker promoter. We showed that using a vector pool containing promoters of variable strength can be a powerful tool for rapidly identifying the best producer for a given protein of interest.

Keywords: Yarrowia lipolytica, Protein production, RedStar2, Glucoamylase, Xylanase, Hybrid promoters

\section{Background}

Increasing the efficiency of heterologous gene expression is a major goal for the agrifood, bioconversion, and pharmaceutical industries as they have a growing need for recombinant proteins. Expression systems using yeasts

*Correspondence: remi.dulermo@ifremer.fr; jean-marc.nicaud@inra.fr; christophe.leplat.01@gmail.com

Micalis Institute, INRA-AgroParisTech, UMR1319, Team BIMLip: Integrative

Metabolism of Microbial Lipids, Université Paris-Saclay, domaine de

Vilvert, 78350 Jouy-en-Josas, France present several advantages: yeasts are easy to manipulate, they are unicellular organisms with rapid growth rates, and they are eukaryotes that can incorporate posttranslational modifications. In addition to the more conventional Saccharomyces cerevisiae [1], alternative model species are also used as biofactories, including Pichia pastoris, Hansanula polymorpha, Kluyveromyces lactis, Kluyveromyces marxianus [2-5], and Yarrowia lipolytica $[6,7]$. 
Production systems exploiting Y. lipolytica have several advantages [7, 8]. First, $Y$. lipolytica is a non-pathogenic organism that can grow on a diversity of substrates. Second, the products of several Y. lipolytica-based processes have received the "generally recognized as safe" (GRAS) designation from the FDA. Third, Y. lipolytica has a naturally strong secretory ability $[7,8]$ and demonstrates weak protein glycosylation [9].

Several genetic tools are available to enhance protein expression in $Y$. lipolytica. Indeed, integrative expression cassettes containing different markers, such as $L E U 2$, $U R A 3, A D E 2$, and LYS5, have been constructed. They can be used to transform competent auxotrophic strains of $Y$. lipolytica. Moreover, several promoters are also available, including the constitutive TEF promoter, the constitutive and hybrid hp4d promoter, and the inducible $P O X 2$ and LIP2 promoters [10-14]. In addition, several transformation methods have been developed to optimize the transformation rate [15-17]. Currently, the lithium-acetate method is the most common, whether the goal is to inactivate endogenous genes or to transform expression cassettes [18]. All of these tools have been successfully used in Y. lipolytica to produce such proteins as xylanase, lipase, leucine aminopeptidase II, human interferon, $\alpha 2 b$ endoglucanase II, and cellobiohydrolase II $[6,9,14$, 19, 20]. Past studies have also identified at least three sequences that can be used to optimize protein secretion in Y. lipolytica: preLip2, preXpr2, and preSuc2 $[6,14$, 21-24].

Several studies have suggested that $Y$. lipolytica is better than $P$. pastoris at producing heterologous proteins $[20,25]$. Indeed, Nars and colleagues [25] found that, as opposed to P. pastoris, E. coli, or simple free cells, Y. lipolytica was the best candidate for generating extracellular Lip2 because it can form a stable isotope-labeled version of the protein. Boonvitthya and colleagues [19] compared endoglucanase II and cellobiohydrolase II production in $Y$. lipolytica and P. pastoris. In YT medium, Y. lipolytica produced up to $15 \mathrm{mg} / \mathrm{L}$ of endoglucanase and $50 \mathrm{mg} / \mathrm{L}$ of cellobiohydrolase. Furthermore, the enzymes produced by Y. lipolytica had higher levels of specific activity than did their counterparts in P. pastoris. Finally, it has been found that $Y$. lipolytica has weaker protein glycosylation than does $P$. pastoris [9].

One of the first strong constitutive promoters was developed by Novo, using the TEF1 gene, which encodes the translation elongation factor-1 $\alpha$ [10]. Later, Madzak and colleagues [26] identified the upstream activating sequence UAS1 in the XPR2 gene (which encodes the secreted alkaline extracellular protease). This discovery led to the development of the hp4d promoter, which is based on the minimal LEU2 promoter and contains four UAS1 tandem elements; with this promoter, expression increases as the number of UAS1 tandem elements increases. More recently, several research groups have used this basic model (i.e., multiple UAS tandem elements associated with a core promoter) to develop improved promoters [27-29]. It has been found that the core promoter and the upstream activating sequence (i.e., the UAS1 tandem elements) act independently and that, as previously noted, promoter strength increases with the number of UAS1 tandem elements. Shabbir Hussain and colleagues [29] showed that promoter strength can be fine-tuned by engineering the sequences of the TATA box, the core promoter, or the upstream activating region. To quantify promoter strength, they used fluorescent proteins and $\beta$-galactosidase assays.

However, to our knowledge, no study to date has used these UAS1-based promoters to produce proteins of industrial interest. Here, we used two conventional promoters, $\mathrm{p} T E F$ and hp4d, as well as five new hybrid promoters of our own construction. To create the latter, we added two, three, four, or eight UAS1 tandem elements to $\mathrm{pTEF}$; we also added four tandem elements to hp4d. Promoter strength in transformed $Y$. lipolytica strains was quantified using RedStar2, a fluorescent protein, as a reporter; we also analyzed the production of secreted Aspergillus niger glucoamylase (GA) and xylanase $\mathrm{C}$ $(\mathrm{XlnC})$. GA is a glucan 1,4-alpha-glucosidase that belongs to the glycosyl hydrolase family. It catalyzes the degradation of starch and other complex sugars, releasing D-glucose. GA is largely used to produce biolipids and bioethanol from starch or lignocellulosic materials [30, 31]. $\mathrm{X} \ln C$ is a beta-1,4-beta-xylanase that breaks down hemicellulose, a component of plant cell walls, releasing xylose. The paper, textile, and pet-food industries are major consumers of xylanase.

Our results revealed that optimal protein expression, secretion, and activity are not always correlated with promoter strength. Consequently, we developed a simple method for improving protein expression that involves the use of a pool of vectors containing promoters of variable strength.

\section{Methods}

Yeast strains, growth media, and culture conditions

The Y. lipolytica wild-type strain W29 (ATCC20460) was used as the basis for all the Y. lipolytica strains built in this study (see Additional file 1: Table S1 for the full list). The auxotrophic strain Pold $\left(\mathrm{Leu}^{-} \mathrm{Ura}^{-}\right.$) has previously been described by Barth and Gaillardin [19]. Escherichia coli strain DH5 $\alpha$ was used to construct the plasmids, except in the case of vectors containing $c c d B$, for which E. coli strain DB3.1 was used. E. coli growth media and culture conditions have been previously described by Sambrook and colleagues [32], and those for Y. lipolytica 
have been described by Barth and Gaillardin [15]. Rich medium (YPD) and minimal glucose medium (YNB) were prepared as described elsewhere [33]. The YPD medium contained $10 \mathrm{~g} / \mathrm{L}$ of yeast extract (Difco, Paris, France), $10 \mathrm{~g} / \mathrm{L}$ of Bacto Peptone (Difco, Paris, France), and $10 \mathrm{~g} / \mathrm{L}$ of glucose (Sigma Aldrich, Saint-Quentin Fallavier, France). The YNB medium contained $1.7 \mathrm{~g} / \mathrm{L}$ of yeast nitrogen base without amino acids and ammonium sulfate (YNBww; Difco, Paris, France), $10 \mathrm{~g} / \mathrm{L}$ of glucose (Sigma), $5.3 \mathrm{~g} / \mathrm{L}$ of $\mathrm{NH}_{4} \mathrm{Cl}$, and $50 \mathrm{mM}$ phosphate buffer ( $\mathrm{pH}$ 6.8). This minimal medium was supplemented with uracil $(0.1 \mathrm{~g} / \mathrm{L})$ and/or leucine $(0.1 \mathrm{~g} / \mathrm{L})$ as necessary. $\mathrm{YP}_{2} \mathrm{D}_{4}$ medium contained $10 \mathrm{~g} / \mathrm{L}$ of yeast extract (Difco, Paris, France), $20 \mathrm{~g} / \mathrm{L}$ of Bacto Peptone (Difco, Paris, France), and $40 \mathrm{~g} / \mathrm{L}$ of glucose (Sigma Aldrich, SaintQuentin Fallavier, France). Solid media were created by adding $1.6 \%$ agar.

\section{Plasmid and strain construction}

The structure of the plasmids constructed in this study was typical of that of the expression vector JMP62 [6] (Fig. 1a). The plasmids contained an excisable marker (the I-sceI fragment flanked by LoxP/LoxR [37]), and the promoter and gene of interest were carried in the ClaI-BamHI and BamHI-AvrII fragments, respectively. The zeta region for expression cassette integration was flanked by the NotI site, which is involved in the release of the expression cassette prior to transformation. Plasmid and strain construction are described in Additional file 2: Figure S1. In most cases, the genes of interest were introduced by digesting the corresponding donor plasmid using BamHI-AvrII (Additional file 2: Figure S1a). Promoter exchange was performed by digesting the donor plasmid using ClaI-BamHI; ClaI was used to insert the modified promoter (Additional file 2: Figure S1b).

The two, three, or four UAS1 tandem element fragments were amplified by PCR using $\mathrm{HYB}-\mathrm{ClaI}{ }^{\prime} \mathrm{Hp} 4 \mathrm{~d} 5^{\prime}$ and HYB-BstbI5 ${ }^{\prime} \mathrm{Hp} 4 \mathrm{~d} 3^{\prime}$ as primers (Table 1; Additional file 2: Figure S1). The corresponding fragments were ligated into $\mathrm{pCR} 4 \mathrm{Blunt}^{-\mathrm{TOPO}}{ }^{\circledR}$ in accordance with the manufacturer's instructions (Invitrogen, Saint-Aubin, France).

GA was cloned into the JMP2482, JMP2484, JMP2397, JMP2607, JMP2471, and JMP2473 plasmids at the BamHI and AvrII restriction sites, yielding JMP3781 (LEU2ex 2UAS1-pTEF-GA), JMP3782 (LEU2ex 3UAS1-pTEFGA), JMP3783 (LEU2ex 4UAS1-pTEF-GA), JMP3784 (LEU2ex 8UAS1-pTEF-GA), JMP3785 (LEU2ex hp4d$G A$ ), and JMP3786 (LEU2ex hp8d-GA), respectively.

$X \ln C$ was cloned into the JMP2482, JMP2484, JMP2397, JMP2607, JMP2471, and JMP2473 plasmids at the BamHI and AvrII restriction sites, yielding the JMP3096 (LEU2ex 2UAS1-pTEF-XlnC), JMP3097

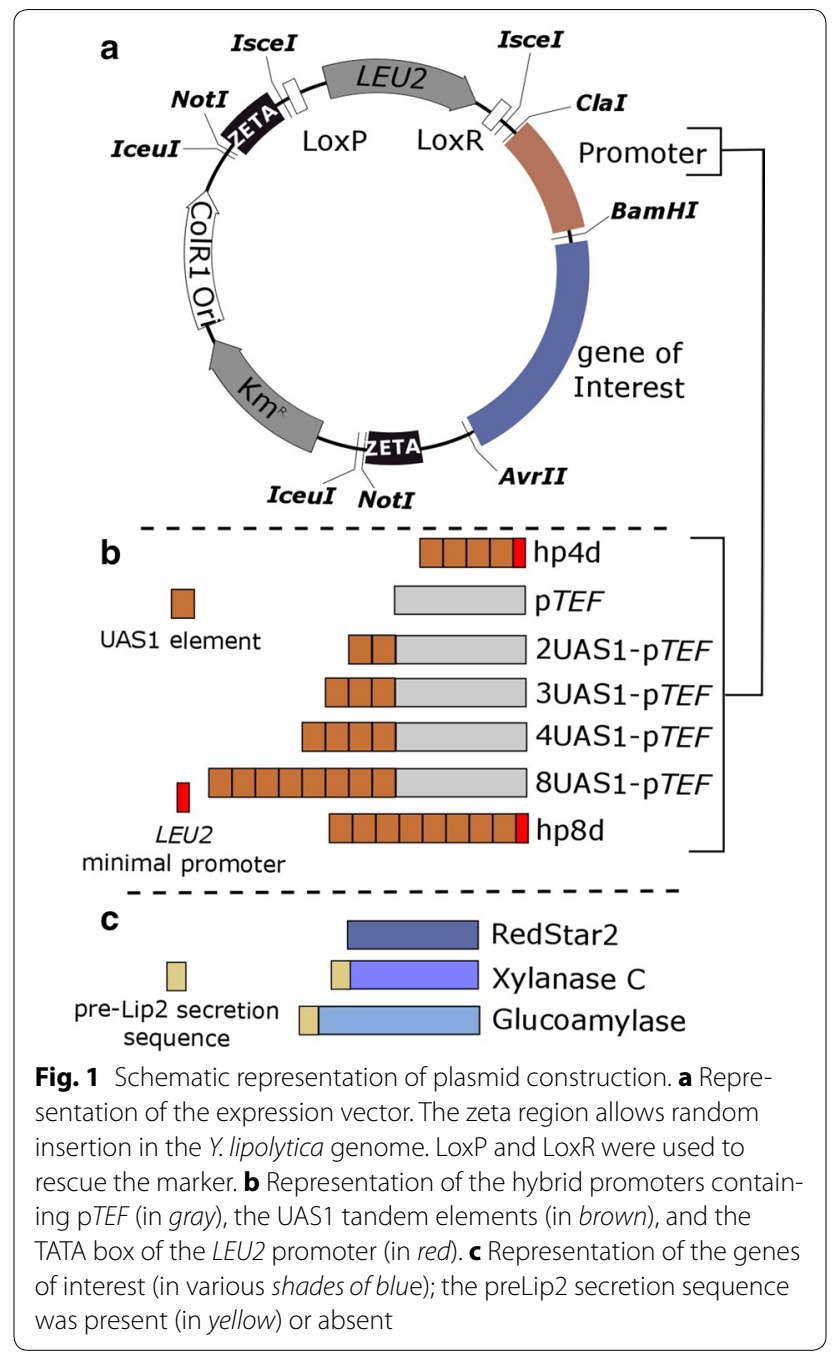

(LEU2ex 3UAS1-pTEF-XlnC), JMP3098 (LEU2ex 4UAS1-pTEF-XlnC), JMP3099 (LEU2ex 8UAS1-pTEF$X \ln C)$, JMP3100 (LEU2ex hp4d- $X \ln C)$, and JMP3101 (LEU2ex hp8d-XInC) plasmids, respectively.

The sequences of the genes encoding YFP and $\alpha$-amylase are provided in Additional file 3: Data S1. These genes were inserted into $\mathrm{pENTR}^{\mathrm{TM}} / \mathrm{D}-\mathrm{TOPO}^{\circledR}$ in accordance with the manufacturer's instructions using the primers listed in Table 1.

The overexpression cassettes, obtained by digesting the plasmids with NotI, were used to transform individual strains via the lithium-acetate method [18]. Transformants were selected utilizing YNB Ura, YNB Leu, or YNB medium, depending on their genotype, and their genomic DNA was prepared as described by Querol and colleagues [34]. The primers used to verify expression cassette insertion are given in Table 1.

Restriction enzymes were obtained from OZYME (Saint-Quentin-en-Yvelines, France). PCR was performed 
Table 1 List of primers used in this study

\begin{tabular}{|c|c|c|}
\hline Primer & Sequence & Use \\
\hline HYB-Clal3'Hp4d5' & CCCTACATCGATACGCGTGC & \multirow[t]{2}{*}{ Hybrid promoter construction } \\
\hline HYB-Bstbl5'Hp4d3' & CCTTCGAACGCACTTTTTGCCCGTGATCAG & \\
\hline GATO_Amont_Clal_for & CCCTGTTATCCCTAGAATCGAT & \multirow{4}{*}{$\begin{array}{l}\text { Verification of plasmid construction and insertion into the } Y \text {. } \\
\text { lipolytica genome }\end{array}$} \\
\hline GATO_Aval_Avrll_rev & TTAGATACCACAGACACCCTAG & \\
\hline GATO_pTEF_BamHI_for & AACTCACACCCGAAGGATCC & \\
\hline GATO_HP4d_BamHI_for & GAACCCGAAACTAAGGATCC & \\
\hline YFP-pool-Fw & CACCATGGTGAGCAAGGGCGAGGAGC & \multirow[t]{2}{*}{ Insertion of YFP gene into pENTR ${ }^{\mathrm{TM}} / \mathrm{D}-\mathrm{TOPO}{ }^{\circledR}$} \\
\hline YFP-pool-Rv & TTACTTGTACAGCTCGTCCATGCC & \\
\hline Amy-pool-Fw & CACCATGAAGCTGTCTACCATTCTG & \multirow[t]{2}{*}{ Insertion of a-amylase gene into pENTR ${ }^{\mathrm{TM}} / \mathrm{D}-\mathrm{TOPO}^{\circledR}$} \\
\hline Amy-pool-Rv & TCAAATCTTCTCCCAAATAGCG & \\
\hline 1529BamHIcorrigéF & CCTTGTCAACTCACACCCGAAGGATCCATCACAAGTTTGTAC & \multirow{3}{*}{$\begin{array}{l}\text { Addition of a BamHI site close to the promoter in JMP1529 to } \\
\text { obtain JMP3030 }\end{array}$} \\
\hline 1529BglllcorrigéR & TCTGGCTTTTAGTAAGCCAGATCTACGCGTTTACGCCCCGCC & \\
\hline 1529BamHIcorrigéR & GTACAAACTTGTGATGGATCCTTCGGGTGTGAGTTGACAAGG & \\
\hline qPCR_XInCF & CGAGCTGCCGATCCCAATGCC & \multirow[t]{2}{*}{ qPCR related to the $X \ln C$ gene } \\
\hline qPCR_XInCR & GCTCCACCGCCTGCAGACA & \\
\hline qPCR_YALIOD08272F & AGGCCCAGTCCAAGCGAGGT & \multirow[t]{2}{*}{$\mathrm{qPCR}$ related to the actin gene } \\
\hline qPCR_YALIOD08272R & TCGGTGAGCAGGACGGGGTG & \\
\hline
\end{tabular}

using an Eppendorf 2720 thermal cycler; GoTaq DNA polymerases (Promega, Madison, WI, USA) were employed to verify the results and PyroBest DNA polymerases (Takara, Saint-Germain-en-Laye, France) were employed to carry out cloning. PCR and DNA fragment purification were performed as previously described [35]. The amounts of DNA obtained were measured using MySpec (VWR, Fontenay-sous-Bois, France). All the reactions were performed in accordance with the manufacturer's instructions. The sequencing of the cloned fragments was performed by GATC Biotech (Konstanz, Germany). Clone Manager software was used for the gene sequence analysis (Sci-Ed Software, Morrisville, NC, USA).

\section{Plasmid pool}

Forty $\mathrm{ng} / \mu \mathrm{L}$ of each of the recipient plasmids was mixed with $\mathrm{pENTR}^{\mathrm{TM}} / \mathrm{D}-\mathrm{TOPO}^{\circledR}$ containing the YFP or $\alpha$-amylase gene. The transfer of the genes of interest was performed using LR Clonase ${ }^{\circledR}$ in accordance with the manufacturer's instructions (Invitrogen, Saint-Aubin, France). The mixture was used to transform $E$. coli strain DB3.1. The resulting transformants were then pooled, and their DNA was extracted and digested before Y. lipolytica was transformed in turn.

\section{Sds page}

Supernatant was obtained from cultures grown for $72 \mathrm{~h}$ in $\mathrm{YNB}, \mathrm{YPD}$, or $\mathrm{YP}_{2} \mathrm{D}_{4}$ media and was concentrated tenfold in $30 \mathrm{mM}$ Tris ( $\mathrm{pH} \mathrm{8.0)}$ and $50 \mathrm{mM} \mathrm{NaCl}$ using Amicon Ultra-0.5 $10 \mathrm{~K}$ centrifugal filters (Merck Millipore
Ltd, Ireland). Protein production was analyzed via polyacrylamide gel electrophoresis (SDS-PAGE); 4-12\% Tris-Glycine gels and an XCell SureLock ${ }^{\mathrm{TM}}$ Mini-Cell electrophoresis system (Novex, Life Technologies, SaintAubin, France) were used. Prism (MW1; 19-130 kDa) and wide-range (MW2; 14-212 kDa) protein molecular weight markers were used as standards (VWR Chemicals, Fontenay-sous-Bois, France). The gels were stained with $0.2 \%$ Coomassie Brilliant Blue R dye (Thermo Fisher Scientific, Villebon-sur-Yvette, France).

\section{Protein content}

Twenty- $\mu \mathrm{L}$ samples were analyzed for protein content using the Coomassie (Bradford) Protein Assay Kit (Thermo Fisher Scientific, Villebon-sur-Yvette, France) in accordance with the manufacturer's instructions.

\section{Glucoamylase activity}

GA activity was measured as previously described [36], with the following modifications. Samples containing $40 \mu \mathrm{L}$ of supernatant were incubated for $2-10 \mathrm{~min}$ with $1.8 \mathrm{~mL}$ of a $0.2 \%$ soluble cornstarch solution $\left(30^{\circ} \mathrm{C}, \mathrm{pH}\right.$ $5)$. The resulting glucose concentration was determined via high-performance liquid chromatography: an UltiMate $^{\circledR} 3000$ system (Dionex-Thermo Fisher Scientific, UK) with an Aminex HPX87H column coupled to an RI detector was used. The column was eluted with $0.01 \mathrm{~N}$ $\mathrm{H}_{2} \mathrm{SO}_{4}$ at room temperature and a flow rate of $0.6 \mathrm{~mL} /$ min. Identification and quantification were achieved via comparison to standards. Enzyme activity was expressed in $\mathrm{U} \mathrm{mL} / \mathrm{L}$ of supernatant, where one unit of $\mathrm{GA}$ 
activity $(1 \mathrm{U})$ was defined as the amount of GA required to release $1 \mu \mathrm{mol}$ of glucose per minute.

\section{Xylanase activity}

$\mathrm{X} \ln \mathrm{C}$ activity was determined using the EnzChek ${ }^{\circledR}$ Ultra Xylanase Assay Kit (Molecular Probes Invitrogen Ltd., Paisley, UK) in $30 \mathrm{mM}$ Tris $(\mathrm{pH} 8.0)$ and $50 \mathrm{mM} \mathrm{NaCl}$ at $25{ }^{\circ} \mathrm{C}$ in a BioLector ${ }^{\circledR}$ (Biotek, Colmar, France). Prior to the assays, supernatant from cultures grown in YNB medium was diluted 50- and 100-fold, and supernatant from cultures grown in YPD or $\mathrm{YP}_{2} \mathrm{D}_{4}$ was diluted 500and 1000-fold. As in the case of GA, one unit of XlnC activity $(1 \mathrm{U})$ was defined as the amount of $\mathrm{X} \ln C$ required to release $1 \mu \mathrm{mol}$ of xylose per minute.

\section{Growth analysis}

The growth of the $Y$. lipolytica strains was analyzed using a microtiter plate reader, as previously described [37]. RedStar2 fluorescence and YFP fluorescence were analyzed at emission wavelength settings of 558 and $586 \mathrm{~nm}$, respectively; the reception wavelength settings were 505 and $530 \mathrm{~nm}$, respectively.

\section{Microscopic analysis}

Images were acquired using a Zeiss Axio Imager M2 microscope (Zeiss, Le Pecq, France) and Axiovision v. 4.8 software (Zeiss, Le Pecq, France).

\section{qPCR analysis}

RNA extraction was performed using the RNeasy Mini Kit (Qiagen, Courtaboeuf, France) followed by DNA digestion with DNase I (RNase-free; New England BioLabs, Evry, France). cDNA synthesis was performed with the Maxima First Strand cDNA Synthesis Kit with dsDNase (Thermofisher Scientific, Courtaboeuf, France). PCR quantification was performed with CFX Connect $^{\mathrm{TM}}$ Real-Time PCR Detection System (Bio-Rad, Marnes-la-Coquette, France) using the SsoAdvanced ${ }^{\mathrm{TM}}$ Universal SYBR ${ }^{\circledR}$ Green Supermix Kit (Bio-Rad, Marnesla-Coquette, France). The number of $\mathrm{X} \ln \mathrm{C}$ mRNA copies was determined using the cycle threshold $(\mathrm{Ct})$ values, which were standardized using results for the expression of the actin gene (YALI0D08272g); the number of XlnC mRNA copies found in the strain containing $\mathrm{p} T E F-X \ln C$ was employed as a reference.

\section{Results and discussion}

\section{RedStar2 expression varies with promoter strength}

To examine how protein expression varied with promoter strength, we constructed seven promoters (see diagram in Fig. 1b). Two were conventional promoters: pTEF and hp4d. Four new hybrid promoters were generated by combining two, three, four, or eight UAS1 tandem elements taken from hp4d with the TEF promoter, yielding 2UAS1-pTEF, 3UAS1-pTEF, 4UAS1-pTEF, and 8UAS1-pTEF, respectively (Fig. 1b). We also created a derivative of the hp4d promoter by adding four supplementary UAS1 tandem elements, thus generating hp8d (Fig. 1b).

Based on previous studies, hp4d and $\mathrm{p} T E F$ should be the weakest promoters, while hp8d and 8UAS1-pTEF should be the strongest. All of these promoters were ligated into a JMP62-LEU2 plasmid containing the LEU2 marker and a long-terminal-repeat zeta element that allows random insertion in Y. lipolytica (Fig. 1a) [38]. RedStar2 was used as a reporter system to measure promoter strength (Fig. 1c); it was chosen because the protein's fluorescence is easy to detect and quantify in Y. lipolytica $[35,39,40]$. RedStar2 fluorescence was analyzed by microscopy (Fig. 2a) and using a Biotek BioLector $^{\circledR}$ (Fig. 2b, c). Since all the strains showed similar growth patterns (Fig. 2c), their fluorescence levels could be compared. As expected, there was a correlation between putative promoter strength and strain fluorescence (Fig. 2a, b): the stronger the promoter, the greater the fluorescence. Therefore, the strains containing hp4d and pTEF had the weakest fluorescence, while the strains containing hp $8 \mathrm{~d}$ and $8 \mathrm{UAS} 1-\mathrm{p} T E F$ had the strongest fluorescence. Over time, the fluorescence of strains containing hp8d and 8UAS1-pTEF increased 2.3- and 5.3-fold compared to their respective controls, the strains containing hp4d and pTEF. Therefore, our results show that increasing the number of UAS1 tandem elements in hybrid promoters resulted in a gradual increase in RedStar2 expression levels (Fig. 2b), confirming the previous findings of Blazeck and colleagues $[27,28]$. Thus, our seven promoters varied greatly in strength: there was a 29-fold difference between the weakest ( $\mathrm{p} T E F$ : $4000 \mathrm{AU})$ and strongest promoter (php8d: 115,000 AU) (Fig. 2b).

\section{Promoter strength affects xylanase $\mathrm{C}$ production but not glucoamylase production}

We used GA and XlnC to examine how our promoters could be used to produce proteins of industrial interest. GA is used to degrade lignocellulosic materials, the starch in oligosaccharides, or glucose, and it can thus be used by microorganisms to produce biolipids, bioethanol, and other bioindustrial materials [30, 31, 41]. XlnC is a commonly used enzyme in bioprocesses in the paper, textile, and pet-food industries. Therefore, enhancing its production could be of great interest. GA and $\mathrm{X} \operatorname{lnC}$ activity are also easy to measure (see refs. [42, 43] for GA and "Methods" section for XlnC), making them good candidates for examining the relationship between protein production and promoter strength. To facilitate 


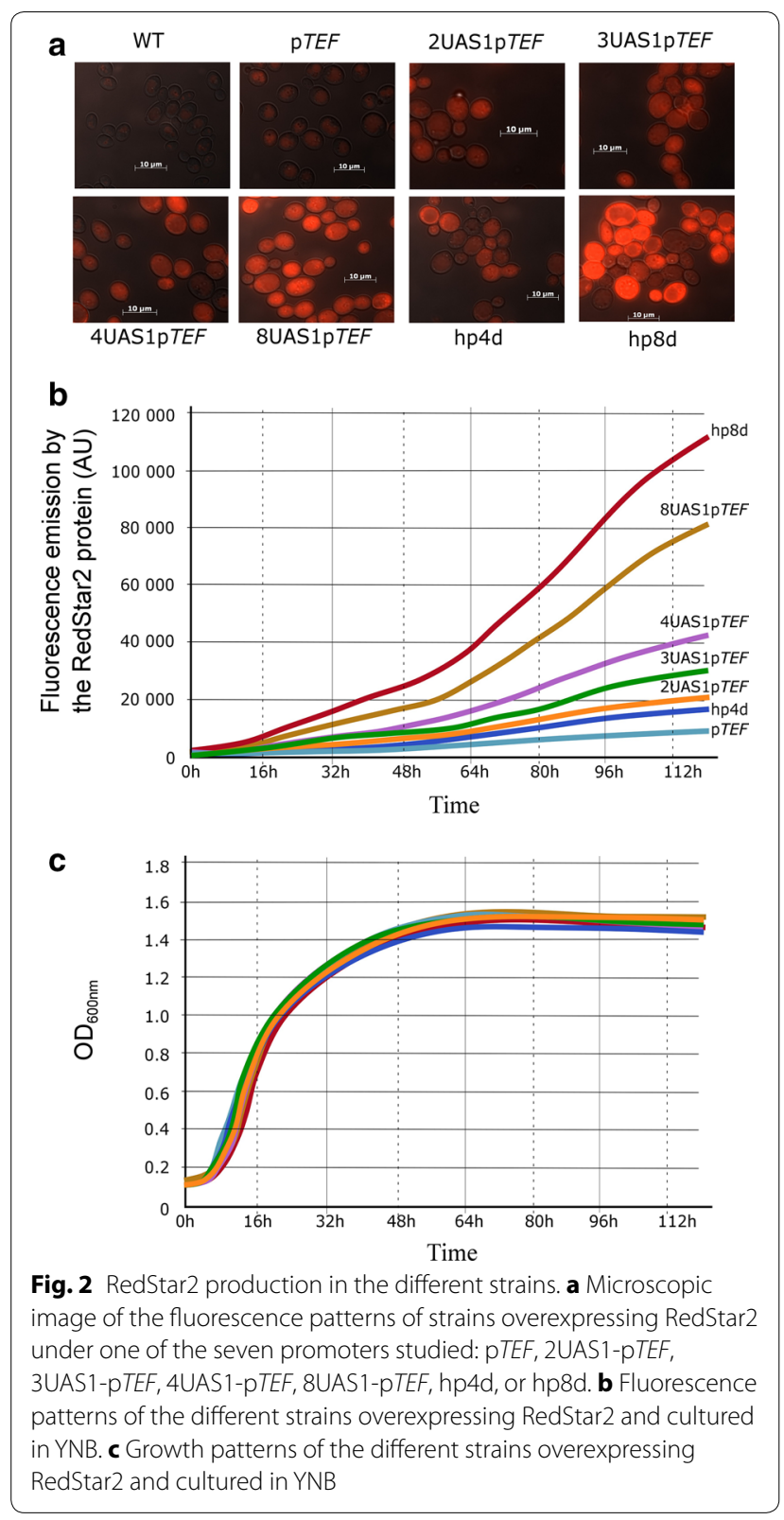

our analyses (i.e., the visualization of the electrophoresis results and the interpretation of the enzyme assays), the preLip2 secretion sequence was added to the $G A$ and $X \ln C$ genes. This sequence allows proteins to be secreted into the growth medium $[6,14,30]$. Both genes were cloned into different vectors containing the seven different promoters, which were subsequently used to transform $Y$. lipolytica. Cultures were then grown in three media - a defined medium, YNB; a rich medium, YPD; and a very rich medium, $\mathrm{YP}_{2} \mathrm{D}_{4}$-and the levels of secreted GA and $\mathrm{X} \ln C$ were analyzed (Fig. 3; Additional file 4: Figure S2, Additional file 5: Table S2).

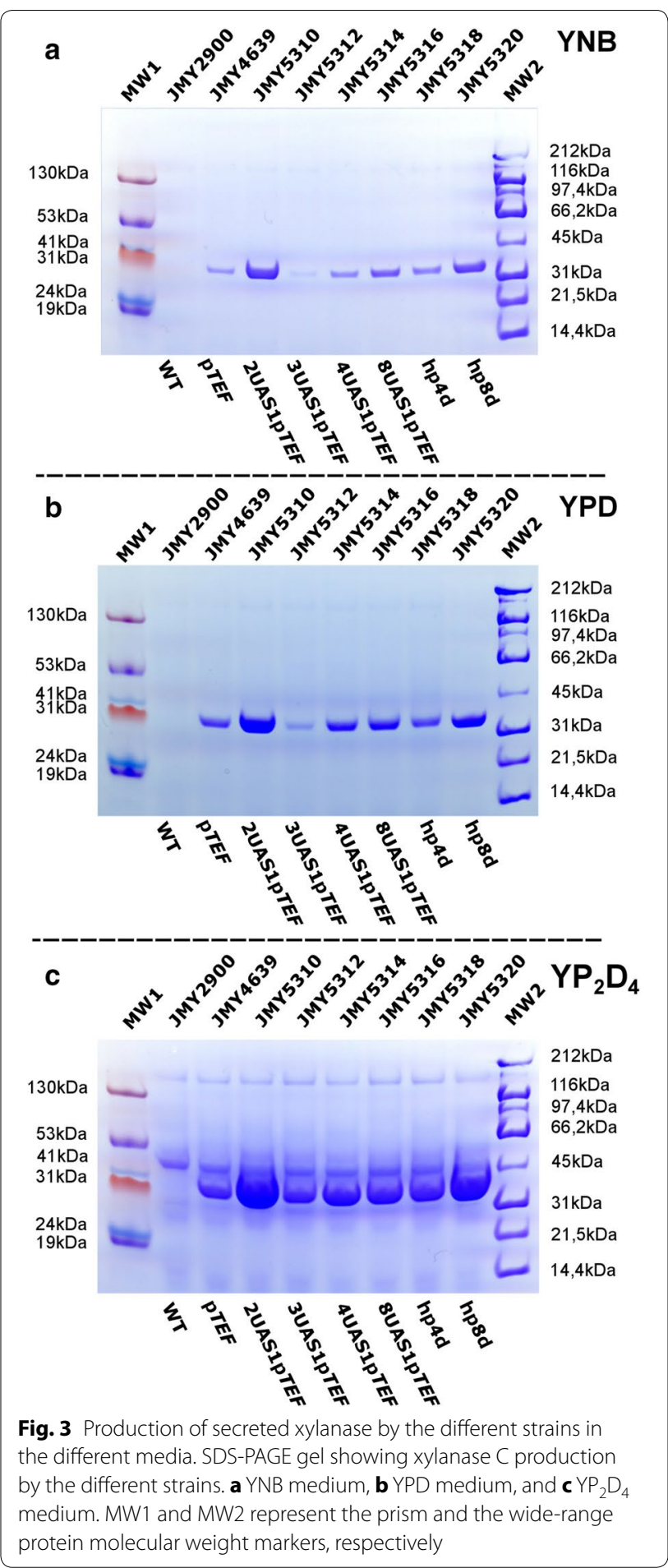

As expected, GA production varied with promoter strength and increased with medium richness (Additional file 4: Figure S2a-d). However, high production levels may or may not translate into high activity levels. To determine if there was a correlation between the two 
variables, GA activity was estimated by measuring the disappearance of starch and the appearance of glucose. Activity was found to be positively associated with production (Additional file 4: Figure S2e).

In contrast, $\mathrm{X} \ln \mathrm{C}$ production was not associated with promoter strength. Indeed, across all media, thicker bands were observed for strains containing 2UAS1-pTEF and, to a lesser extent, hp8d, whereas band thickness was equivalent for strains containing 3UAS1-pTEF, 4UAS1pTEF, 8UAS1-pTEF, and hp4d (Figs. 3, 4a; Additional file 5: Table S2). The results were consistent when additional transformants were analyzed. Semi-quantitative

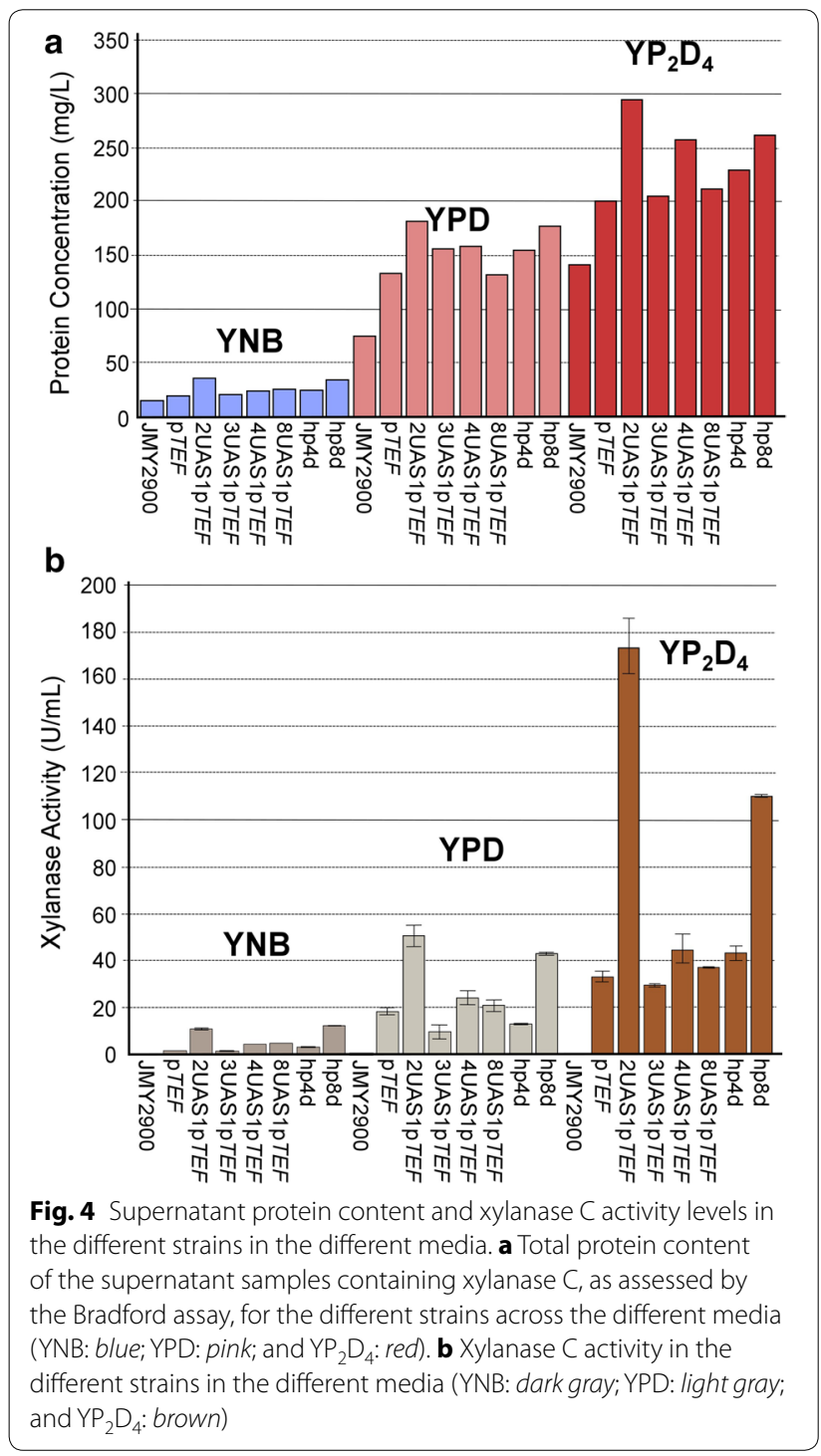

PCR confirmed that only one copy of $X \ln C$ was inserted into the genome of the strain containing 2UAS1-pTEF (data not shown). Interestingly, we found that $\mathrm{X} \ln \mathrm{C}$ production was 2-4 times higher in the strain containing 2UAS1-pTEF than in the strains containing $\mathrm{p} T E F$, 8UAS1-pTEF, and hp4d. In our experiment, in $\mathrm{YP}_{2} \mathrm{D}_{4}$, maximum XlnC production was about $153 \mathrm{mg} / \mathrm{L}$. The strain containing $8 \mathrm{UAS1} 1 \mathrm{p} T E F$ produced slightly more $\mathrm{X} \operatorname{lnC}$ than the strains containing 3UAS1-pTEF and 4UAS1-pTEF when the yeasts were cultured in YNB. However, its levels of production were similar or lower when the yeasts were cultured in YPD or $\mathrm{YP}_{2} \mathrm{D}_{4}$. In various microorganisms, several bottlenecks in heterologous protein production have been identified; they include transcription, protein folding and glycosylation, translocation, signal peptide processing, and proteolysis [41-43]. Therefore, several hypotheses could explain why 2UAS1-pTEF was the best promoter for XlnC production. To evaluate if this result could be attributed to the 2UAS1-pTEF promoter resulting in higher levels of $X \ln C$ transcription, $\mathrm{X} \ln C \mathrm{mRNA}$ levels were analyzed using qRT-PCR (Fig. 5). However, mRNA levels were positively correlated with promoter strength. This result is consistent with those of a previous study [44], in which researchers observed that the production of an insulin precursor and of amylase was lower under the TEF1 promoter than under the TPI promoter even though their

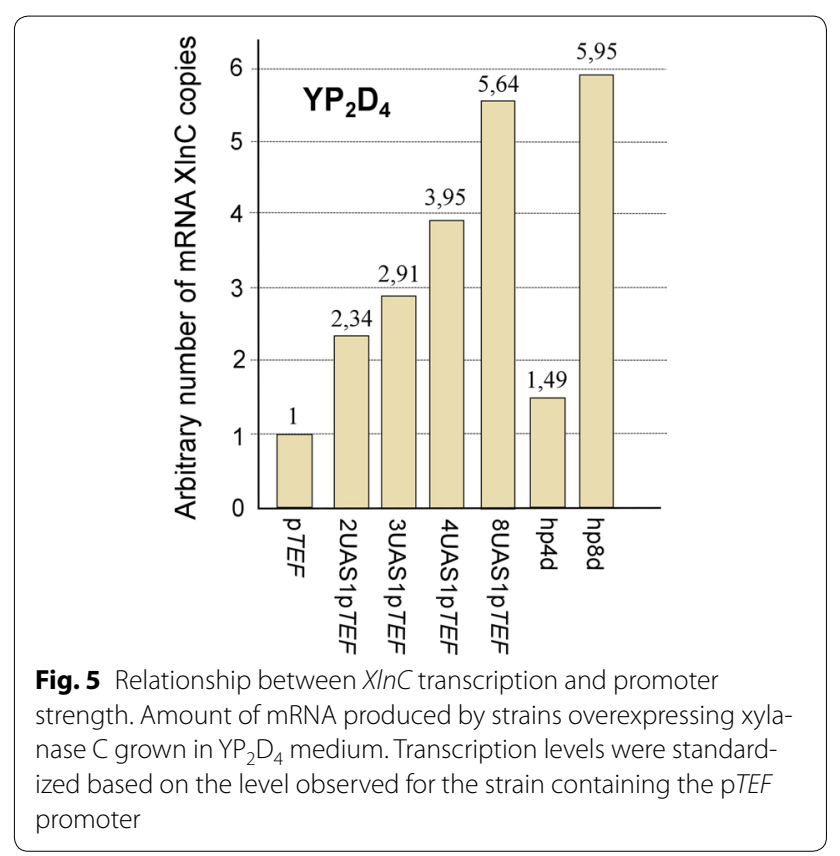


transcription was greater under the TEF1 promoter. However, it is possible that the use of promoters stronger than 2UAS1-pTEF could have resulted in excessive protein production, which could have negatively affected protein folding because of the titration of chaperon proteins and the saturation of secretion machinery, as found previously [43].

As for GA, we examined the correlation between $\mathrm{X} \operatorname{lnC}$ production and activity (Fig. 4b). As expected, the WT strain, JMY2900, demonstrated no XlnC activity. Surprisingly, activity levels were not always associated with production levels, which could suggest that there was co-secretion of non-active or less-active forms of the enzyme. Although the two variables were correlated when the strains were grown in YNB, the correlation was weak or completely absent when the strains were grown in $\mathrm{YP}_{2} \mathrm{D}_{4}$ or YPD, respectively (Fig. $4 \mathrm{a}, \mathrm{b}$ ). For instance, the strain containing 3UAS1-pTEF had a production level similar to that of the strain containing 4UAS1-pTEF, but the former's activity level was much lower. Indeed, its activity level resembled that of the strain containing $\mathrm{p} T E F$. Interestingly, activity levels were 1.5-2 times higher than expected for the strains containing 2UAS1-pTEF and hp8d (Fig. 4b). Oddly, although these promoters increased protein production two to fourfold, compared to the strain containing $\mathrm{p} T E F$, activity increased three to sixfold (Fig. 4a, b; Additional file 5: Table S2, Additional file 6: Table S3). These results underscore that enzyme expression, production, and activity are not always linearly related to promoter strength. Indeed, these relationships may vary and depend on the specific enzyme and growth medium used.

\section{A gateway vector pool for selecting the best protein producer}

Since promoter strength was not necessarily correlated with heterologous protein production, we decided to develop a method for rapidly identifying transformants with optimized production; we used a pool of vectors containing promoters that varied in strength. To simplify the approach, we employed a gateway system that allowed in vitro cloning and the counter-selection of the correct clone using CcdB toxicity. We constructed a derivative of the gateway plasmid JMP1529 described in Leplat et al. [39]: JMP3030 (gateway-ClaI-pTEF-BamHI). Derivatives were constructed using ClaI-BamHI-based promoter exchange (Additional file 1: Table S1).

We analyzed the expression of YFP and secreted $\alpha$-amylase (Fig. 6). Briefly, we first inserted the genes

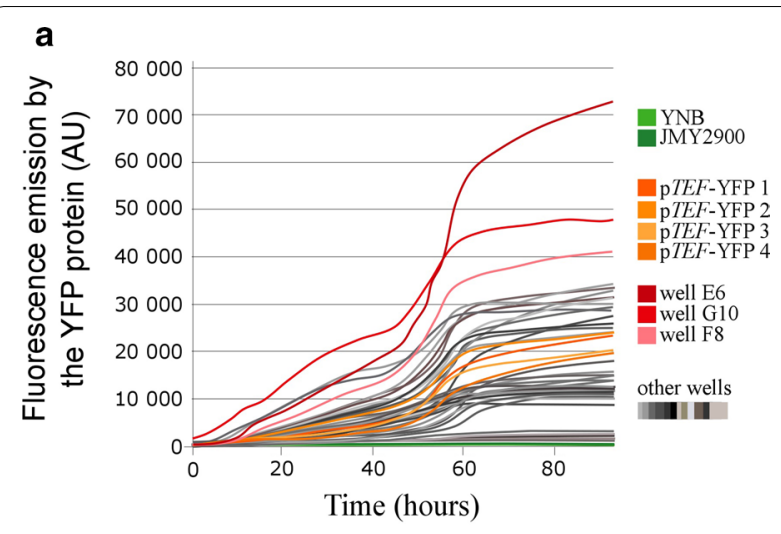

b

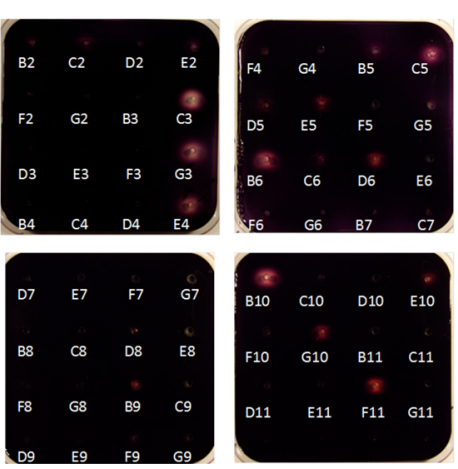

Fig. 6 Results of the vector-pool method when used to identify clones with enhanced YFP and a-amylase production. a Fluorescence patterns of the strains overexpressing YFP. The figure depicts the negative controls (i.e., the wild-type strain, Y2900, and yeast transformants grown on YNB), the positive controls (the 4 strains overexpressing YFP via PTEF), and the 54 strains obtained by the transformation of Y. lipolytica via the pool of vectors. The most interesting results are associated with clones E6, G10, and F8. b Starch consumption patterns for the strains overexpressing a-amylase. The figure depicts the negative controls (B2: yeast grown on YNB and C2: the wild-type strain, Y2900), the positive controls (D2, E2, F2, and G2: the 4 strains overexpressing a-amylase via the TEF promoter), and the 54 strains produced by the transformation of $Y$. lipolytica via the pool of vectors. Starch consumption was measured using iodine crystals

encoding YFP and $\alpha$-amylase into $\mathrm{pENTR}^{\mathrm{TM}} / \mathrm{D}-\mathrm{TOPO}^{\circledR}$. We then transferred these genes into a pool of vectors using LR Clonase ${ }^{\circledR}$ (Additional file 7: Figure S3). After transforming $Y$. lipolytica, we analyzed 54 clones for YFP and $\alpha$-amylase expression (Fig. 6). We found that some clones displayed higher activity levels than others-YFP activity was especially high for the E6, G10, and F8 clones (72,000 U; 48,000 U; and 41,000 U, respectively), and $\alpha$-amylase activity was especially high for the C3, G3, E4, B6, B10, and F11 clones. Analysis of the promoters 
involved in the expression of these genes revealed that most of the clones contained a promoter that was stronger than pTEF (Table 2). Indeed, with the exception of G10, which contained pTEF, the clones contained hp4d, hp8d, 4UAS-pTEF, or 8UAS-pTEF. However, in some cases, it was difficult to identify the promoter since sequencing was impaired by the multiple UAS1 tandem elements and there was not enough differentiation among fragment sizes to use a PCR-based approach. Therefore, we have proposed two candidate promoters for B6 ( $\alpha$-amylase) and E6 (YFP). Using this method, we have identified several good producers for both enzymes, which shows that it could be very helpful to use a pool of plasmid vectors containing variable-strength promoters to obtain strains that have optimal activity levels.

\section{Conclusions}

Blazeck and colleagues [27, 28] developed very strong promoters to optimize protein expression in $Y$. lipolytica; however, these promoters were only used to

Table 2 Promoters upstream of the a-amylase gene and YFP gene in the different clones

\begin{tabular}{ll}
\hline & Promoter \\
\hline a-Amylase & \\
C3 & 4UAS1-pTEF \\
G3 & hp4d \\
E4 & hp8d \\
B6 & 3 UAS1-pTEF or 4UAS1-pTEF \\
B10 & 8UAS1-pTEF \\
F11 & 8UAS1-pTEF \\
YFP & \\
E6 & $4 U$ US1-pTEF or hp8d \\
F8 & 8UAS1-pTEF \\
G10 & pTEF \\
\hline
\end{tabular}

The clone names are the same as in Fig. 6 produce intracellular proteins, such as fluorescent proteins, or in $\beta$-galactosidase assays. We constructed similar versions of these promoters (pTEF, 2UAS1-pTEF, 3UAS1-pTEF, 4UAS1-pTEF, 8UAS1-pTEF, hp4d, and hp8d) and analyzed their impact on the production of intracellular proteins, namely RedStar2 and YFP, as well as extracellular proteins, namely glucoamylase, xylanase $C$, and $\alpha$-amylase (see summary in Table 3 ). We found that, most of the time, having the strongest promoter (8UAS-pTEF) resulted in the highest levels of protein production and activity (i.e., in the cases of RedStar2, glucoamylase, YFP, and $\alpha$-amylase). However, the best promoters for xylanase $\mathrm{C}$ were 2UAS1-pTEF and hp8d. Our results show that stronger promoters do not always optimize protein production and activity. It could be that either transcriptional or post-translational regulation, such as RNA processing and stability, translation efficiency, or protein stability and modification $[45,46]$, places limits on this relationship. As a result, multiple promoters should always be tested. To limit clone number and keep the process simple, we developed a straightforward strategy for accomplishing this aim: exploiting a pool of vectors containing promoters of different strengths. Cloning was facilitated by using the gateway system and LR Clonase ${ }^{\circledR}$. Indeed, in a single step, it was possible to obtain a collection of vectors containing variable-strength promoters upstream from the gene of interest. Once the study organism has been transformed, screening tests can be used to select the best strains. This approach could be very helpful to those seeking to improve protein production, whether in a research or an industrial setting. The pool should contain a decent number of promoters and include inducible promoters, which could be particularly important when dealing with toxic proteins.

Table 3 Relative results for the experiments examining RedStar2, glucoamylase, and xylanase C expression under the seven different promoters studied

\begin{tabular}{|c|c|c|c|c|c|c|}
\hline & \multirow{2}{*}{$\begin{array}{l}\text { Redstar2 } \\
\text { Activity }\end{array}$} & \multicolumn{2}{|l|}{ GA } & \multicolumn{3}{|l|}{$X \ln C$} \\
\hline & & Production & Activity & RNA & Production & Activity \\
\hline pTEF & + & + & + & + & + & + \\
\hline 2UAS-pTEF & ++ & ++ & ++ & ++ & +++++ & +++++ \\
\hline 3 UAS-pTEF & +++ & ++ & ++ & +++ & \pm & + \\
\hline 4UAS-pTEF & ++++ & +++ & +++ & ++++ & + & + \\
\hline 8UAS-pTEF & +++++ & ++++ & ++++ & +++++ & +++ & + \\
\hline hp4d & ++ & + & ++ & + & ++ & + \\
\hline hp8d & +++++ & +++ & ++++ & +++++ & ++++ & +++ \\
\hline
\end{tabular}

The number of crosses indicate very low $( \pm)$, low $(+)$, medium $(++)$, high $(+++)$, very high $(++++)$ and extremely high $(+++++)$ levels 


\section{Additional files}

Additional file 1: Table S1. Details on the strains and plasmids used in this study.

Additional file 2: Figure S1. Schematic representation of plasmid and strain construction.

Additional file 3: Data S1. Sequences of the genes used in this study.

Additional file 4: Figure S2. Production and activity of secreted glucoamylase for the different strains in the different media.

Additional file 5: Table S2. Glucoamylase and xylanase C concentrations.

Additional file 6: Table S3. Xylanase activity levels.

Additional file 7: Figure S3. Schematic representation of the construction of the vector pool.

\section{Abbreviations}

GA: glucoamylase; XInC: xylanase C; YFP: yellow fluorescent protein; PCR: polymerase chain reaction.

\section{Authors' contributions}

RD: wrote the project proposal, designed the experiments, built some of the plasmids and strains, performed the RedStar2 experiment, performed the vector-pool experiment, analyzed the results, and wrote the manuscript; FB: built the different promoters as well as some of the plasmids and strains and performed the RedStar2 experiment; TD: wrote the project proposal; RLA: performed the test for GA activity; JV: built some of the strains and performed the vector-pool experiment; MT: quantified protein production and ran the related gels; ST: built some of the plasmids and strains; JM: wrote the project proposal and designed the experiments; $\mathrm{CL}$ : wrote the project proposal, designed the experiments, built some of the plasmids and strains, performed the RedStar2 experiment, quantified protein production, ran the related gels, performed the test for XInC activity, carried out quantitative PCR, analyzed the results, and wrote the manuscript. All authors read and approved the final manuscript.

\section{Acknowledgements}

We thank the French government for giving us IDEX funding (Grant No 20150445I). R. Ledesma-Amaro received financial support from the European Union (Marie-Curie FP7 COFUND People Program: AgreenSkills Fellowship). We thank Jessica Pearce and Lindsay Higgins for their language editing services.

\section{Competing interests}

The authors declare that they have no competing interests.

\section{Availability of data and materials}

Data sharing is not relevant as no datasets were generated or analyzed during the current study.

\section{Funding}

C. Leplat received IDEX funding (Grant No 2015-0445I), which paid for all the experiments and J. Vion's salary. R. Ledesma-Amaro received financial support from the European Union (Marie-Curie FP7 COFUND People Program: AgreenSkills Fellowship).

Received: 26 August 2016 Accepted: 10 February 2017 Published online: 17 February 2017

\section{References}

1. Domínguez A, Fermiñán E, Sánchez M, González FJ, Pérez-Campo FM, García S, Herrero AB, San Vicente A, Cabello J, Prado M, Iglesias FJ, Choupina A, Burguillo FJ, Fernández-Lago L, López MC. Non-conventional yeasts as hosts for heterologous protein production. Int Microbiol. 1998;1:131-42.
2. Madhavan A, Sukumaran RK. Promoter and signal sequence from filamentous fungus can drive recombinant protein production in the yeast Kluyveromyces lactis. Bioresour Technol. 2014;165:302-8.

3. Bragança CR, Colombo LT, Roberti AS, Alvim MC, Cardoso SA, Reis KC, de Paula SO, da Silveira WB, Passos FM. Construction of recombinant Kluyveromyces marxianus UFV-3 to express dengue virus type 1 nonstructural protein 1 (NS1). Appl Microbiol Biotechnol. 2015;99:1191-203.

4. Spohner SC, Schaum V, Quitmann H, Czermak P. Kluyveromyces lactis: an emerging tool in biotechnology. J Biotechnol. 2016;222:104-16.

5. Wagner JM, Alper HS. Synthetic biology and molecular genetics in nonconventional yeasts: current tools and future advances. Fungal Genet Biol. 2016;89:126-36.

6. Nicaud JM, Madzak C, van den Broek P, Gysler C, Duboc P, Niederberger P, Gaillardin C. Protein expression and secretion in the yeast Yarrowia lipolytica. FEMS Yeast Res. 2002;2:371-9.

7. Madzak C, Gaillardin C, Beckerich JM. Heterologous protein expression and secretion in the non-conventional yeast Yarrowia lipolytica: a review. J Biotechnol. 2004;109:63-81.

8. Nicaud JM. Yarrowia lipolytica. Yeast. 2012;29:409-18.

9. Madzak C, Beckerich JM. Heterologous protein expression and secretion in Yarrowia lipolytica. In: Yarrowia lipolytica, vol. 25. Berlin: Springer; 2013. p. 1-76.

10. Müller S, Sandal T, Kamp-Hansen P, Dalbøge H. Comparison of expression systems in the yeasts Saccharomyces cerevisiae, Hansenula polymorpha, Klyveromyces lactis, Schizosaccharomyces pombe and Yarrowia lipolytica. Cloning of two novel promoters from Yarrowia lipolytica. Yeast. 1998;14:1267-83.

11. Madzak C, Treton B, Blanchin-Roland S. Strong hybrid promoters and integrative expression/secretion vectors for quasiconstitutive expression of heterologous proteins in the yeast Yarrowia lipolytica. Mol Microbiol Biotechnol. 2000;2:207-16.

12. Nthangeni MB, Urban P, Pompon D, Smit MS, Nicaud JM. The use of Yarrowia lipolytica for the expression of human cytochrome P450 CYP1A1. Yeast. 2004;21:583-92.

13. Sassi H, Delvigne F, Kar T, Nicaud JM, Coq AM, Steels S, Fickers P. Deciphering how LIP2 and POX2 promoters can optimally regulate recombinant protein production in the yeast Yarrowia lipolytica. Microb Cell Fact. 2016;15:159

14. Gasmi N, Fudalej F, Kallel H, Nicaud JM. A molecular approach to optimize hIFN a2b expression and secretion in Yarrowia lipolytica. Appl Microbiol Biotechnol. 2011;89:109-19.

15. Barth G, Gaillardin C. Yarrowia lipolytica. In: Wolf K, editor. Non conventional yeasts in biotechnology, vol. 1. Springer: Germany; 1996. p. 313-88.

16. Chen DC, Beckerich JM, Gaillardin C. One-step transformation of the dimorphic yeast Yarrowia lipolytica. Appl Microbiol Biotechnol. 1997:48:232-5.

17. Xuan JW, Fournier P, Gaillardin C. Cloning of the LYS5 gene encoding saccharopine dehydrogenase from the yeast Yarrowia lipolytica by target integration. Curr Genet. 1988;14:15-21.

18. Le Dall MT, Nicaud JM, Gaillardin C. Multiple-copy integration in the yeast Yarrowia lipolytica. Curr Genet. 1994;26:38-44.

19. Boonvitthya N, Bozonnet S, Burapatana V, O'Donohue MJ, Chulalaksananukul W. Comparison of the heterologous expression of Trichoderma reesei endoglucanase II and cellobiohydrolase II in the yeasts Pichia pastoris and Yarrowia lipolytica. Mol Biotechnol. 2013;54:158-69.

20. Wang W, Wei H, Alahuhta M, Chen X, Hyman D, Johnson DK, Zhang M, Himmel ME. Heterologous expression of xylanase enzymes in lipogenic yeast Yarrowia lipolytica. PLoS ONE. 2014;9:e111443.

21. Hong SP, Seip J, Walters-Pollak D, Rupert R, Jackson R, Xue Z, Zhu Q Engineering Yarrowia lipolytica to express secretory invertase with strong FBA1 IN promoter. Yeast. 2012;29:59-72.

22. De Pourcq K, Vervecken W, Dewerte I, Valevska A, Van Hecke A, Callewaert $\mathrm{N}$. Engineering the yeast Yarrowia lipolytica for the production of therapeutic proteins homogeneously glycosylated with Man 8 GlcNAc 2 and Man5 GlcNAc2. Microb Cell Fact. 2012;11:53.

23. Lazar Z, Rossignol T, Verbeke J, Crutz-Le Coq AM, Nicaud JM, Robak M Optimized invertase expression and secretion cassette for improving Yarrowia lipolytica growth on sucrose for industrial applications. J Ind Microbiol Biotechnol. 2013;40:1273-83. 
24. Moon HY, Van TL, Cheon SA, Choo J, Kim JY, Kang HA. Cell-surface expression of Aspergillus saitoi-derived functional a-1,2-mannosidase on Yarrowia lipolytica for glycan remodeling. J Microbiol. 2013;51:506-14.

25. Nars G, Saurel O, Bordes F, Saves I, Remaud-Siméon M, André I, Milon A, Marty A. Production of stable isotope labelled lipase Lip2 from Yarrowia lipolytica for NMR: investigation of several expression systems. Protein Expr Purif. 2014;101:14-20

26. Madzak C, Blanchin-Roland S, Cordero Otero RR, Gaillardin C. Functional analysis of upstream regulating regions from the Yarrowia lipolytica XPR2 promoter. Microbiology. 1999;145:75-87.

27. Blazeck J, Liu L, Redden H, Alper H. Tuning gene expression in Yarrowia lipolytica by a hybrid promoter approach. Appl Environ Microbiol. 2011;77:7905-14.

28. Blazeck J, Reed B, Garg R, Gerstner R, Pan A, Agarwala V, Alper HS. Generalizing a hybrid synthetic promoter approach in Yarrowia lipolytica. Appl Microbiol Biotechnol. 2013;97:3037-52.

29. Shabbir Hussain M, Gambill L, Smith S, Blenner MA. Engineering promoter architecture in oleaginous yeast Yarrowia lipolytica. ACS Synth Biol. 2016;5:213-23.

30. Ledesma-Amaro R, Dulermo T, Nicaud JM. Engineering Yarrowia lipolytica to produce biodiesel from raw starch. Biotechnol Biofuels. 2015;8:148.

31. Mehmood N, Husson E, Jacquard C, Wewetzer S, Büchs J, Sarazin C, Gosselin I. Impact of two ionic liquids, 1-ethyl-3-methylimidazolium acetate and 1-ethyl-3-methylimidazolium methylphosphonate, on Saccharomyces cerevisiae: metabolic, physiologic, and morphological investigations. Biotechnol Biofuels. 2015;8:17.

32. Sambrook J, Maniatis T, Fritsch EF. Molecular cloning: a laboratory manual. 2nd ed. Cold Spring Harbor: Cold Spring Harbor Laboratory Press; 1989.

33. Mlícková K, Roux E, Athenstaedt K, d'Andrea S, Daum G, Chardot T, Nicaud JM. Lipid accumulation, lipid body formation, and acyl coenzyme A oxidases of the yeast Yarrowia lipolytica. Appl Environ Microbiol. 2004;70:3918-24.

34. Dulermo R, Gamboa-Meléndez H, Michely S, Thevenieau F, Neuvéglise C, Nicaud JM. The evolution of Jen3 proteins and their role in dicarboxylic acid transport in Yarrowia. Microbiologyopen. 2015;4:100-20.
35. Querol A, Barrio E, Huerta T, Ramón D. Molecular monitoring of wine fermentations conducted by active dry yeast strains. Appl Environ Microbiol. 1992;58:2948-53.

36. Dulermo R, Gamboa-Meléndez H, Ledesma-Amaro R, Thévenieau F, Nicaud JM. Unraveling fatty acid transport and activation mechanisms in Yarrowia lipolytica. Biochim Biophys Acta. 2015;1851:1202-17.

37. Viktor MJ, Rose SH, van Zyl WH, Viljoen-Bloom M. Raw starch conversion by Saccharomyces cerevisiae expressing Aspergillus tubingensis amylases. Biotechnol Biofuels. 2013;6:167.

38. Pignède G, Wang H, Fudalej F, Gaillardin C, Seman M, Nicaud JM. Autocloning vectors for gene expression and amplification for the yeast $Y$. lipolytica. Appl Environ Microbiol. 2000;66:3283-9.

39. Leplat C, Nicaud JM, Rossignol T. High-throughput transformation method for Yarrowia lipolytica mutant library screening. FEMS Yeast Res. 2015;15:fov052.

40. Dulermo R, Gamboa-Meléndez H, Dulermo T, Thevenieau F, Nicaud JM. The fatty acid transport protein Fat1p is involved in the export of fatty acids from lipid bodies in Yarrowia lipolytica. FEMS Yeast Res. 2014;14:883-96.

41. Idiris A, Tohda H, Kumagai H, Takegawa K. Engineering of protein secretion in yeast: strategies and impact on protein production. Appl Microbio Biotechnol. 2010;86:403-17.

42. Li W, Zhou X, Lu P. Bottlenecks in the expression and secretion of heterologous proteins in Bacillus subtilis. Res Microbiol. 2004;155:605-10.

43. Ahmad M, Hirz M, Pichler H, Schwab H. Protein expression in Pichia pastoris: recent achievements and perspectives for heterologous protein production. Appl Microbiol Biotechnol. 2014;98:5301-17.

44. Liu Z, Tyo KE, Martínez JL, Petranovic D, Nielsen J. Different expression systems for production of recombinant proteins in Saccharomyces cerevisiae. Biotechnol Bioeng. 2012;109:1259-68.

45. Greenbaum D, Colangelo C, Williams K, Gerstein M. Comparing protein abundance and mRNA expression levels on a genomic scale. Genome Biol. 2003;4:117

46. Vogel C, Marcotte EM. Insights into the regulation of protein abundance from proteomic and transcriptomic analyses. Nat Rev Genet. 2012;13:227-32.

\section{Submit your next manuscript to BioMed Central and we will help you at every step:}

- We accept pre-submission inquiries

- Our selector tool helps you to find the most relevant journal

- We provide round the clock customer support

- Convenient online submission

- Thorough peer review

- Inclusion in PubMed and all major indexing services

- Maximum visibility for your research

Submit your manuscript at www.biomedcentral.com/submit
() Biomed Central 